Res Publica. Revista de Historia de las Ideas Políticas

ISSN-e: 1989-6115

http://dx.doi.org/10.5209/rpub.66182

\title{
Refugiados del siglo XVIII: malestar de frontera y de género en Hermann y Dorothea (1797) de Johann Wolfgang von Goethe*
}

\author{
Nuria Sánchez Madrid**
}

Recibido: 2 de mayo de 2019 / Aceptado: 4 de octubre de 2019

Resumen. Las obras en que Goethe se ocupa de los desastres de la guerra y del sufrimiento de los refugiados ponen de manifiesto una percepción de la normatividad social en la que la crisis no se reconoce nunca como una resistencia que no pueda ser sometida por la subjetividad. Este trabajo se ocupa en primer lugar de ofrecer una interpretación de las consideraciones de Goethe acerca del campo de batalla postrevolucionario en Francia y Alemania y la experiencia de desclasamiento y de racismo cultural que genera. En segundo lugar, me centraré en el idilio Hermann y Dorothea para señalar de la mano de la transformación sufrida en esta obra por el personaje de Dorothea las limitaciones del planteamiento de la condición de la mujer que Goethe lleva a cabo en ella. Finalmente, propongo emplear las obras de Goethe mencionadas como hilo conductor para acceder a su percepción del orden civil y a la destinación que ese marco reserva a la mujer excluida y marginada socialmente en la Alemania del siglo XVIII.

Palabras clave: Goethe; crónica de guerra; orden; refugiados; mujer.

\section{[en] Refugees of the 18th Century: Boundaries and Gender Anxieties in Hermann und Dorothea (1797) by Johan Wolfgang von Goethe}

\begin{abstract}
The writings in which Goethe tackles the disasters of warfare and the suffering of refugees yield a perception of social normativity where crisis is not considered a hindrance impossible to overcome by the subject. This paper focuses first on a reading of Goethe's remarks about the post-revolutionary field of battle in France and Germany and the experience of social downgrade and cultural racism that it entails. Second I shall concentrate in the idyll Hermann and Dorothea to highlight through the transformation undergone by the role of Dorothea the shortcomings of Goethe's account of the condition of women in this short writing. Finally, I aim at using the mentioned works of Goethe as a thread helpful to approach his perception of civil order and the destiny that this pattern assigns to women in circumstances of social exclusion and marginalization in XVIIIth Century Germany.
\end{abstract}

Keywords: Goethe; War chronicle; Order; Refugees; Woman.

\footnotetext{
* El trabajo ha sido realizado con el apoyo de los proyectos New Trust-cm (H2015-HUM-3466), financiado por la Comunidad de Madrid, Pensamiento y representación literaria y artística digital ante la crisis de Europa y el Mediterráneo (PR26/16-6B-3), financiado por la UCM/Santander y del Proyecto de Innovación Educativa Precariedad, exclusión y diversidad funcional. Lógicas y efectos subjetivos del sufrimiento social contemporáneo (PIMCD UCM 2018, n. ${ }^{\circ}$ 148). Pertenece asimismo a la investigación iniciada en el marco de la ayuda 2019 para Humanidades Digitales concedida por el BBVA al equipo investigador liderado por J.L. Villacañas, del que soy miembro. Agradezco a dos evaluadores anónimos de la revista Res publica sus útiles comentarios sobre distintos aspectos del artículo, que me permitieron mejorar la calidad del texto.

** Universidad Complutense de Madrid nuriasma@ucm.es
} 
Sumario: 1. Mantener la calma en tiempos convulsos: la divisa de Goethe en Campagne in Frankreich y Die Belagerung von Mainz. 2. Una mujer bajo la influencia: Dorothea y la violencia ética burguesa. 3. Conclusiones

Cómo citar: Sánchez Madrid, N. (2019). Refugiados del siglo XVIII: malestar de frontera y de género en Hermann y Dorothea (1797) de Johann Wolfgang von Goethe, en Res Publica 22.3, 673-686.

Si algo imprime un sello peculiar a la prosa y los versos que Johann Wolfgang von Goethe dedicó a la catástrofe y a los cruentos espectáculos que depara al espectador la contienda bélica entre Napoleón y las regiones alemanas de la cuenca del Rin ${ }^{1}$, esa divisa podría formularse como el anhelo de que la subjetividad humana cierre las heridas de su espíritu con la elegancia de las huellas que tales procesos guardan en la naturaleza. La violencia desatada por las tropas francesas en suelo alemán anima en la pluma de Goethe a emprender una suerte de reconstrucción de lo que está mal en el mundo mediante las solas fuerzas del siempre prometeico espíritu. Semejante deseo satisface sin duda las expectativas de sana supervivencia de un mundo burgués poseedor de un talante predominantemente pragmático, que lo vuelve sabedor de la necesidad de negociar con los ideales revolucionarios de la misma manera en que la naturaleza devuelve un paisaje cíclico en que la tormenta y el apaciguamiento se alternan. Basta con que el espíritu de la construcción, que actuará asimismo como bajo continuo de otra obra de Goethe como es Fausto, marque su predominio sobre el desastre y el daño de los que procede. Me interesa enfocar desde el comienzo, especialmente de la mano de un idilio burgués como es el poema en hexámetros Hermann und Dorothea (1797), lo que este itinerario tiene de salida en falso para figuras como la muchacha refugiada Dorothea, un personaje sin origen claro y de precario estatus social en el escrito, forzada en la trama goethiana a corresponder y asimilarse a las condiciones que le impone la familia que condesciende a "protegerla" de los peligros que acechan en la Alemania postrevolucionaria.

\section{Mantener la calma en tiempos convulsos: la divisa de Goethe en Campagne in Frankreich y Die Belagerung von Mainz}

El contacto con una realidad brusca y displicente con el mos maiorum siempre resulta extenuante para Goethe. Las páginas que se dedican en Die Belagerung von Mainz a detallar la fuente de inspiración de la que mana esta breve obra, junto con otras temáticamente emparentadas, desemboca así con alivio en un comentario elocuente acerca de lo que la escritura de Reinecke Fuchs supone para su autor, tras lo que califica de sobredosis de imágenes de plazuela, populacho y escenas callejeras, a saber, una línea de fuga con respecto a las angustias del presente:

\footnotetext{
Una selección de ensayos de interés para proceder a una reconstrucción histórica de las semblanzas presentadas por Goethe en Campagne auf Frankreich y Die Belagerung von Mainz puede ser la siguiente: G. Seibt, Mit einer Art von Wut. Goethe in der Revolution, München, 2014; D. Borchmeyer, Weimarer Klassik. Portrait einer Epoche, Weinheim, 1994; Ibidem, Goethe. Der Zeitbürger, München 1999 y N. Boyle, Goethe. Der Dichter in seiner Zeit, Bd. II, 1791-1803, München, 1999. El acercamiento que este trabajo realiza a tales obras no es ni biográfico ni histórico, pero hemos tenido en cuenta las obras mencionadas para evitar posibles consideraciones anacrónicas.
} 
[E]ra ahora realmente sanador para mí el contemplar aquel espejo de cortes y de príncipes, pues aunque la especie humana se mostrara allí de un modo natural en su bestialidad sincera, todo ocurría de una manera alegre, ya que no ejemplar, y el buen humor no se sentía perturbado por nada ${ }^{2}$.

Seguramente la composición de una obra como Reinecke Fuchs, con su componente de crítica de la vida cortesana, pero también de alivio frente a la experiencia directa del campo de batalla, venía a responder al motto Auch ich in der Campagne!, que en 1822 remedaba el Auch ich in Arkadien! de Italienische Reise (1786-1788). Como había señalado Kant en el $\S 48$ de su $K U$, una realidad que no permite rodearse con la distancia de la representación estética solo sería merecedora del asco [Ekel], incapaz de generar ninguna inspiración para el gusto. Incapaz de precipitar los acontecimientos de la Historia Universal, al poeta solo le quedaba aspirar a proteger su ánimo apesadumbrado por la impresión de que el mundo nunca se había encontrado más ensangrentado y ávido de destrucción ${ }^{3}$. Ese propósito de mantener en reserva un tesoro personal inasequible al desencanto también guía, aunque con mayor exposición a los acontecimientos de actualidad en 1797, la composición del idilio que, en la estela de la Luise de Johann Heinrich Voss, hace a Goethe sentirse, por confesión propia, el último de los homéridas, tal y como recoge el prólogo en hexámetros que compuso años después de la publicación de Hermann y Dorothea. La recepción de esta breve obra, ya desde la recensión publicada por August Wilhelm Schlegel, se empleó a fondo para cortar los posibles nexos con el poema pastoral de Voss, perfectamente integrado en una suerte de Ilustración rural, que alberga el deseo de configurar el alma nacional alemana con ayuda del retorno a la naturaleza ${ }^{4}$. Pero el retorno de Goethe a Homero, como Voss había recreado los idilios de Teócrito a decir de Wieland, respondía a las angustias del presente. Recordemos que en tiempos de la guerra civil española Rafael Sánchez Mazas redactará su Rosa Krüger, que une el destino del varón con la estilización de la esposa buscada y no la realmente elegida, en una suerte de antropología del amor al servicio de la proyección ibérica del fascismo. El patriarcado y el ideal kantiano de la paz se conjugan a mi juicio en la pieza goethiana, con la esperanza de rehacer el deteriorado cañamazo del tejido civil $\mathrm{o}$, si se prefiere, la decisión poética de Goethe hace de la solidez de las costumbres el mejor fármaco frente al proceso calificado por Cicerón como inter arma silent leges.

En esta primera sección del escrito es mi propósito argumentar que el personaje trágico por excelencia de este elogio de la burguesía como motor de convivencia civil es claramente la muchacha Dorothea, en quien pueden reconocerse muchos rasgos de la Ifigenia que Goethe versificara en 1787 a partir del material euripideo, si bien es patente y un seductor motivo de análisis la disyuntiva de desenlaces ex-

J.W. von Goethe, "Die Belagerung von Mainz", en Sämtliche Werke, Berlin, Propyläen Verlag, 1827, Bd. 34, p. 341. Todas las traducciones de los pasajes citados de "Campagne in Frankreich" y "Die Belagerung von Mainz" son mías.

3 Sobre la reacción poética de Goethe ante la aparición de los refugiados franceses y alemanes en la cuenca del Rin debido a las invasiones napoleónicas véase el magnífico análisis de Reinhard Mehring, "Goethes Flüchtlinge. Poetisierung des Dramas”, Zeitschrift für Religions- und Geistesgeschichte 68/4 (2016), pp. 313-333.

4 Sobre la huella de Voss en Goethe, pero también de Zum ewigen Frieden de Kant en Hermann und Dorothea, cf. I. Wagner, "Hermann und Dorothea in the Context of Kant and Voss: A Question of Peace and Patriarchy", Goethe Yearbook 9/1 (1998), pp. 166-185. Cf. F. Sengle, "Luise von Voss und Goethes Hermann und Dorothea. Zur Funktion der Homerisieren”, en Neues zu Goethe. J.B. Metzler, Stuttgart, 1989, pp. 49-68. 
perimentados por una figura femenina en ambas tramas. Mientras Ifigenia insiste en imponer sus propias reglas en un mundo violento y patriarcal, Dorothea acaba por claudicar como la Juana de Arco que ha mostrado su conducta para asumir el rol de la perfecta esposa de un posadero con posibles. Como es bien sabido, las figuras femeninas de Goethe son bien distintas de las que podemos reconocer en las tormentosas y al mismo tiempo altamente lúcidas narraciones de Heinrich von Kleist. En ellas el primero encontró la expresión de una violencia enfermiza y una tendencia general a lo disfuncional y desencajado [Ungefügtes], que no podía sino lanzar un arriesgado pulso a la obsesión ilustrada por la conveniencia [Schicklichkeit]. En esa tendencia, von Kleist no podía sino anunciar a Kafka en su empeño por abrir, por decirlo en las ajustadas palabras de Adorno en Minima Moralia, "perspectivas en las que el mundo aparezca trastocado, enajenado, mostrando sus grietas y desgarros" ". Nada más lejos de la intención de estilo burgués que atraviesa la obra de Goethe y especialmente su representación de un presente ayuno de guía y orientación que dar rienda suelta a la disteleología como clave hermenéutica del mundo.

Partamos de algunas estampas en las que Goethe da cuenta, como el "observador imparcial" que debe aspirar a ser el poeta, de lo que califica como "íntima contradicción" de las masas de emigrados, en buena parte integrados por caballeros de San Luis, en Grevenmacher. Por de pronto los presenta reducidos a cuidar de sí mismos y de sus caballos, a los que -en ausencia de palafreneros- debían llevar al abrevadero o hacer herrar. Las penalidades asociadas al desclasamiento brillan especialmente en numerosas páginas de la Campagne in Frankreich, de la misma manera que la socarronería cargada de prejuicios de género con que Goethe describe la argucia de una anciana para proveer de mínimos cuidados y lecho a una recién parida, mientras él y el duque se encuentran acampados cerca de Sivry:

Como no sabía francés, teníamos que solicitar en su nombre, pero su carácter dominante, su violencia, subrayaban nuestras frases con gran fuerza y expresión pantonímicas: no había modo de traerle con suficiente celeridad cuanto pedía, y lo que le traían no le parecía lo bastante bueno. Por otra parte, era digno de ser visto el modo expeditivo como procedía. Bien pronto nos expulsó del fuego, el mejor asiento fue ocupado enseguida por la parida, mientras que ella se acomodaba en un escabel, como si estuvieran solas en la casa ${ }^{6}$.

La sorpresa de Goethe ante el poder performativo con que una mujer anciana subvierte la ocupación del espacio dictada por los varones y todo el orden que presupone es sumamente elocuente de su codificación de la conducta femenina. Las dos mujeres aludidas, pero especialmente la anciana, decidida a proteger a su hija, son retratadas como sujetos astutos, en condiciones de disputar a los húsares presentes en la hospedería los bienes y provisiones. No hace falta adivinarlo: a juicio de Goethe el llamado sexo débil se aprovecha de su debilidad y desventaja civil. Se trata de una vieja sentencia, que Kant recoge sin reticencias en su Antropología en sentido pragmático (1798) cuando se detiene en la capacidad de la mujer para imponerse mediante la seducción a la llamada del varón, gobernando de veras a pesar de que en apariencia todo indica que es este último quien lo dirige todo en el hogar.

Th. W. Adorno, Minima Moralia, trad. de J. Chamorro, Madrid, Taurus, 1998, p. 250.

J.W. Goethe, "Kampagne in Frankreich", in op. cit., p. 256. 
El pasaje que venimos de citar confirma que Goethe participa de esta percepción de la relación entre sexos. Precisamente por ello hace hincapié en la sorpresa que le supone la desenvoltura con que un sujeto femenino puede imponer su voluntad casi de manera ingenua, desprovista de la sentimentalidad que tradicionalmente ha sido su marca de un proceso en que se imbrican la infamia de la dependencia y el valor de la diferencia. No ahorra tampoco nuestro autor en el arqueo de sus experiencias aquellos momentos en que él mismo se sintió en la piel de un refugiado francés, al ser tomado inicialmente por posaderos hartos de recibir grupos desordenados de emigrantes como un extranjero indeseado. Así lo relata en uno de sus recuerdos de Kassel en Die Belagerung von Mainz, cuando su alegría por hallarse en una ciudad repleta de iluminación y de signos civilizatorios se vio enturbiada por la confusión con un extranjero francés, huido de la zona de guerra:

Sin embargo, esta jovialidad se desvaneció para mí durante algún tiempo, cuando me acerqué en la magnífica Königsplatz a plena luz del día a una conocida posada; el empleado presente me rechazó con la explicación siguiente: no había sitio. Como no me quiso retirar, llegó el posadero muy gentilmente al sonido de la diligencia y se disculpó con algunas frases en francés, indicando que no era posible acogerme. Repliqué a sus palabras en buen alemán: cuánta tenía que ser mi sorpresa ante el hecho de que se denegara la acogida a un forastero en la noche en un edificio tan grande, cuyo espacio conocía bien. ¡Pero usted es un alemán! -exclamó-, ¡eso es otra cosa! E inmediatamente permitió al postillón entrar en el portón?

El texto brinda la ocasión para subrayar la frialdad con que Goethe describe el "racismo cultural" que florece en Alemania ante la llegada de los numerosos refugiados franceses. La experiencia de la desigualdad en el trato dirigido a franceses y alemanes, que él mismo conoce en primera persona, no deja demasiada huella en el ánimo de Goethe, quien reconoce en este mismo escrito preferir la comisión de una injusticia a contribuir a la extensión del desorden. Y lo segundo amenazaba con instalarse en Europa con más velocidad que la tradicional desigualdad entre grupos y clases en el mismo continente. La incomunicación entre los pueblos, con frecuencia amparada en necios prejuicios, es una constante antropológica que Goethe asume como parte de la naturaleza que nos ha sido legada. Una anécdota expone el rostro más caricaturesco de esta hostilidad, al enfocar el desprecio con que unos hambrientos campesinos franceses rechazan las hogazas de pan negro que el alemán les ofrece. En esta ocasión son el gusto y los hábitos lo que aleja al sujeto de la satisfacción del hambre, siendo pocos los que cuentan con las herramientas necesarias para superar este caso patente de injusticia hermenéutica. El "pan negro" y el "pan blanco" se convierten así en el schibboleth respectivo para franceses y alemanes en medio de la incursión del ejército de la Primera Coalición en tierras francesas ${ }^{8}$. El prólogo versificado de Hermann y Dorothea exhorta con todo a que "triunfe el bueno en esta sana generación" a pesar de las tristes imágenes de la época. Un poco antes

J.W. von Goethe, "Campagne in Frankreich" in op. cit., p. 331.

8 Debo a uno de los evaluadores de este trabajo la remisión, útil en este punto, al artículo de J. Röhnert, "Goethes Campagne als Modellfall autobiographischer Selbstbehauptung”, Germanisch-romanische Monatsschrift, 60/1 (2010), pp. 53-70. 
de la redacción del idilio, la baronesa anfitriona de los aristócratas refugiados de Conversaciones de emigrados alemanes (1795) apuntaba justamente a la deficiencia de "educación estética" que mostraban en los momentos de crisis y necesidad los náufragos lanzados al océano por la constitución burguesa:

Vemos a la mayoría de los emigrados llevando a cuestas sus errores y sus ingenuas costumbres en medio de la confusión y nos asombramos ante tal hecho. Pero igual que la tetera no abandona a los viajeros ingleses en ninguna de las cuatro partes del mundo, al resto de la masa de los humanos os acompañan a todas partes orgullosas exigencias, vanidad, engreimiento, impaciencia, terquedad, parcialidad en el juicio y el placer de imponer algo maliciosamente a sus congéneres. [...] ¡Qué raro es que nos aparezca la pura virtud de algún individuo que, de vedad, se sienta impulsado a vivir para los demás, a sacrificarse por los demás! ${ }^{9}$

La acción desconcertada refleja la dimensión más pulsional de cada uno de los sujetos, azuzados por la angustia y el miedo, perversiones de una Sorge que no dejará de acompañar por otra parte a Fausto en su itinerario vital ${ }^{10}$. No es baladí recordar que este escrito de Goethe se publicó en compañía de extractos de "Cartas sobre la educación estética" de Schiller en varios fascículos de Die Horen a lo largo de 1795. En realidad, la denuncia pronunciada por la baronesa escandalizada por la desordenada masa integrada por los emigrantes alemanes apunta a algo muy similar a la capacidad de fractura del amor propio criticado duramente por Rousseau. Nadie parece estar dispuesto a trabajar en reconstruir lo destruido o en superar la privación material y espiritual. Para ello Goethe preconiza por boca de la baronesa que es esencial deponer los paisajes más o menos ideales en que suele encerrar una ética de la convicción [Gesinnungsethik] no acerada en el debate con el otro. El exótico cuento La serpiente verde, que corona las conversaciones en clave boccacciana de los emigrados alemanes que aparecen en esta obra, expone precisamente un proyecto utópico de regeneración de los vínculos civiles, en el que se advierten resonancias de la muchedumbre en continua actividad del quinto acto de la segunda parte del Fausto. Pero Goethe deja asimismo claro allí que no se trata de un proyecto que requiera únicamente de un maestro geómetra o de un buen arquitecto, sino más bien de uno uncido al respeto que la humanidad debe sentir hacia la secreta fuente de todas sus energías, un motor de realidad envuelto asimismo en el misterio. A pesar de que solo uno de los elegidos de la Tierra podría estar en condiciones de actuar como demiurgo de tal maniobra general de regeneración y metamorfosis, Goethe concentra su atención también aquí -ocurrirá también en Fausto-sobre la falta de un pueblo como una de las tragedias que echan a perder la historia de las grandes ideas. En Fausto la construcción de un templo en favor del pueblo se muestra merecedora de la celebérrima frase: "Detente, instante, jeres tan bello!". Así pues, la redirección de las energías anímicas emerge como una de las tareas principales que cabe acometer en beneficio de la reconstrucción de un

J. W. Goethe, Conversaciones de emigrados alemanes, trad. de I. Hernández, Barcelona, Alba, 2006, pp. 16-17.

10 J. W. Goethe, Fausto, trad. de H. Cortés, Madrid, Abada, 2010, vv. 11424-11431 y vv. 11453-11456: "Aunque ni un oído me oyera / resonar en el corazón debiera. / Bajo una cambiante figura / ejerzo un poder que asusta. / En las olas o en las sendas / angustiosa compañera eterna, / siempre hallada sin ser buscada, / tan maldecida como halagada. [...] / Al que alguna vez yo poseo / de nada vale el mundo entero; / eterna oscuridad sobre él se cierne, / el sol ya ni se levanta ni se mete". 
orden civil que parece no encontrar encaje dentro de la historia empírica, siempre rebelde frente a los goznes de la historia ideal ${ }^{11}$.

\section{Una mujer bajo la influencia: Dorothea y la violencia ética burguesa}

En Hermann y Dorothea se dan cita la voluntad de suministrar al ánimo las reflexiones necesarias para superar el sufrimiento generado por la guerra y la de reconstruir los bienes externos en los que se apoya toda existencia que se precie. Para ello era preciso reconocer en la Naturaleza guiños providentes acerca de su cuidado para con los intereses humanos, como recoge una divertida observación de Goethe, tomada el 3 de septiembre de 1792 en Verdún, en la que se describe con todo lujo de detalles la salvación de un almacén de porcelanas en la plaza del mercado tras haber sufrido un bombardeo. La tuché de los antiguos había de sobrevivir en una naturaleza favorable, que el poeta estaba llamado a reconocer en sus síntomas, especialmente en los tiempos de crisis. Un año después de la aparición de Hermann y Dorothea, Wilhelm von Humboldt publica un escrito sobre este idilio ${ }^{12}$. En ese escrito, Humboldt atribuye al idilio burgués de Goethe rasgos propios de la epopeya, al poetizar realidades prosaicas sin perder nunca las exigencias de un estilo elevado:

Penetra en nuestros pensamientos y sentimientos más íntimos y pone a la vista de todos los pliegues de nuestro corazón, parece acompañarnos en el círculo de nuestra vida cotidiana y corriente, pero se mantiene siempre a la necesaria altura poética $^{13}$.

La reine antike Dichtung a la que resuena Hermann y Dorothea a juicio de Humboldt sustituye el Olimpo de los antiguos griegos por las motivaciones latentes en el interior de los corazones humanos, si bien lo consigue dejando un halo de sencilla transición. Pero con todo esta exploración de «las profundidades ocultas de nuestra alma» tendrá que ver poco con el anhelo de un Linneo del inconsciente humano que Schiller preconizara en el relato El delincuente por culpa del honor perdido (1787) o en Die Bänder (1781). Humboldt se admira por el fortalecimiento de la contemplación y la reflexividad presentes en la escritura de Goethe, capaz de captar una "objetividad, totalidad y armonía" anunciadas en el lector por la quietud [Erholung] y emoción [Rührung] suscitadas por el texto, en continuidad con el modelo antiguo. Pero las ocultas motivaciones recogidas por la pluma goethiana responden a un capital simbólico y cultural que a mi entender está más ligado a una burguesía que comienza a ser consciente de su hegemonía social que a una suerte de trasfondo pulsional primitivo que iguala al noble, a individuos como Wilhelm Meister y al emigrado desclasado. Humboldt subraya que el poema de Goethe no debe ser entendido como un idilio, toda vez que en este formato los personajes no superan su estatuto de meros

11 En relación con la percepción de la comunidad que describimos al final de esta sección remitimos al esclarecedor trabajo de J.L. Villacañas, "Freud sobre Fausto: sustituciones de la omnipotencia", Arbor CLXXXIII (723), pp. 123-133.

12 Cf. A. von Humboldt, "Über Goethes Hermann und Dorothea", en Id., Werke, Bd. II, J.G. Cotta'scheBuchhandlung, Stuttgart, 1979.

13 W. von Humboldt, op. cit., p. 214. 
entes naturales, donde "el ser humano está, por así decirlo, enraizado fijamente en el suelo que lo engendró" "14, quedando atado a la naturaleza solo por amor, sin formarse ningún especial vínculo ético. A juicio de Humboldt, el idilio se propone únicamente poner ante la sensación, no ante el espíritu, los aspectos más armónicos de nuestra relación con la naturaleza, a diferencia de la sátira, atenta a la denuncia de sus contradicciones (Humboldt, 1798/1979, pp. 281-282). Frente a estas formas poéticas, la epopeya -en continuidad con la doctrina aristotélica-convierte un muthos trágico, que siempre interpela a la sensación y por ello es la forma suprema de la poesía lírica, en "un estado quieto y más intelectual" 15 . Siempre desde la lectura de Humboldt, Hermann y Dorothea sería un paradigma del modo en que

[e]l estado de ánimo sentimental de los modernos desciende a las oscuras profundidades del ánimo. [...] Pero lo que importa es tratar esto último con suficiente grandeza para cancelar enseguida otra vez esa contradicción ${ }^{16}$.

La épica se transforma así en una confirmación de la vollendete Bildung que hermana a la naturaleza y la cultura, proporcionando al sujeto la confirmación de que su hábitat propio se encuentra cabe los dilemas de la reflexión y las expectativas de su voluntad. La nueva phusis es, pues, la que conduce al padre de Hermann a proyectar una promoción social para su hijo y a Hermann y a Dorothea a un matrimonio que les beneficia a ambos por diferentes razones, con una promesa de violencia y sufrimiento que sin embargo emergen amenazantes como telón de fondo. El nervio de la trama lo constituye la continuidad de un patrimonio familiar alemán, tutelado con tonos folclóricos por un pastor y un boticario, cómplices de la madre y sabios consejeros del hostelero cabeza de familia. Este ambiente es demasiado prosaico, interesado y pragmático desde la perspectiva de un idilio, pero el material antropológico adquiere un sentido renovado como revestimiento artístico de una forma de vida que convierte la seguridad material en sustituto de una paz espiritual que nunca más volverá y signo de un bienestar que se estima imprescindible ${ }^{17}$. Vayamos directamente a la trama de nuestro idilio que se resiste a serlo con el fin de extraer ulteriores detalles sobre la voluntad de Goethe de salvar los fenómenos por medio de la representación poética, que tiene especiales consecuencias en el caso de la figura de Dorothea. Por de pronto, varios elementos naturales de los acontecimientos recogidos en la obra, que cubren poco más de medio día, señalan el dominio de la naturaleza sobre los cuidados humanos. Así, vemos aparecer el peral majestuoso que preside el cercano campo a la

\footnotetext{
W. Humboldt, 1798/1979, p. 279.

W. Humboldt 1798/1979, pp. 270-271.

W. Humboldt, 1798/1979, p. 234.

17 Cf. M. Jiménez Redondo, "Humboldt sobre Hermann y Dorothea de Goethe”, en A. Domínguez Rey y A. Alonso Martos (Eds.), O Soño transparente da lingua, Espiral Maior, 2015, p. 490: "Digo que, a mi juicio, Humboldt se equivoca. Lo que pasa en Hermann y Dorothea es algo distinto de lo que piensa Humboldt. Goethe ha partido de la épica griega. Críticamente se ha asomado con ella a una Modernidad que al trasluz de la épica griega se revela sin sostén y sin quicios; es el hombre quien siempre provisionalmente y siempre de forma precaria ha de dárselo a sí mismo. [...] En cuanto epopeya, su poema es una epopeya mentida. En Hermann y Dorothea, Goethe, de forma crítica y reflexiva, vuelve la espalda a una Modernidad que se muestra como un abismo y a la que se deben tanto esa distancia crítica como esa reflexividad. De la mano de Grecia y Roma, Hermann y Dorothea es una Modernidad que se cuestiona radicalmente a sí mismo y se huye, una Modernidad, por tanto, que genera también esa forma de ser moderno que se mueve en la ambigüedad entre el criticismo radical de la crítica radical de la razón moderna y el reaccionarismo".
} 
posada propiedad de los padres de Hermann, en torno al que la pareja reconstruyó su vida tras un terrible incendio en que sellaron su unión. Pero también la fuente sobre cuyas aguas se enamoran los dos jóvenes, en una imagen de tonos claramente narcisistas, que recuerda la oportunidad de la fórmula lacaniana -"dar lo que no se tiene a quien no es"- y marca el comienzo de las transacciones entre el goce y el deseo. Asimismo, la zarza ardiendo, de resonancias mosaicas, que caracteriza a los ideales revolucionarios del primer novio de Dorothea-quizás una mención velada a la figura del naturalista Georg Forster ${ }^{18}$-, presente en la trama con una intensidad comparable a la del amante fallecido en el cuento Dublineses de Joyce, completa este listado de potentes símbolos paganos y cristianos, que confirma a la subjetividad que es preciso asumir un límite absoluto. Todos giran en torno al enigma del principio y al arcano del restablecimiento del orden en periodos de crisis. Pero el cierre lo pondrá un recordatorio del límite último e insuperable que trae consigo la muerte que pronuncia el boticario para que el padre de Hermann deponga la impaciencia que muestra ante la inminente llegada al hostal de la novia elegida por su hijo. El boticario recupera una vieja advertencia que su padre le dirigía siempre que la impaciencia se apoderaba de él, señalándole de muchacho que tantas prisas por precipitar los acontecimientos solo le conduciría finalmente a la escena de unos carpinteros disponiéndose a fabricar el ataúd que sirviera para enterrarlo bajo tierra una vez cadáver. El párroco de la historia se apresura a otorgar a esta historia su debida hermenéutica cristiana, dotada de cierta resonancia epicúrea:

La imagen de la muerte, que nos conmociona, no es ningún horror para el sabio, ni ningún final feliz para el piadoso; a aquel lo hace retornar a la vida y le enseña a actuar; a este, mirando a la salvación futura, lo confirma en la esperanza. A ambos la muerte se les convierte en vida. El padre de usted hizo mal cuando al muchacho sensible no le mostró en la muerte sino solo la muerte. Muéstrese al joven el valor de la edad y aun de la vejez que maduran con nobleza, y al anciano muéstresele la juventud que de él procede, de modo que a ambos les regocije ese eterno círculo al que pertenecen, y que la vida no encuentre su acabamiento y consumación sino en la vida ${ }^{19}$.

Por el lado de la moraleja cíclica que rodea la historia encontramos una indiferencia hacia los intereses humanos que sin embargo facilita la comunicación entre los sexos, con connotaciones marcadamente eróticas. Por el lado de la cruda realidad que procede del otro lado del Rin, el padre de Hermann comparte una disposición hacia el destino de los refugiados que es trasunto de la de Goethe. Ambos adoptan el pathos de la distancia como actitud necesaria para conciliar el deseo de entregar -“donar a los pobres" [den Armen zu spenden]- con el legítimo propósito de no ser arrastrado por la miseria a emociones que rehúye el ánimo burgués. "La inquietud me es odiosa más que el mismo mal», afirma el dueño de la casa. Una bata de algodón fino y una indiana adornada con flores y forrada de franela serán los bienes de que el mesonero se desprenda con gusto para evitar mancharse con el espectáculo de la miseria ajena, a pesar de que su mujer los ha tomado a escondidas. Más tarde,

18 P. Morgan, "The Polarization of Utopian Idealism and Practical Politics in the Idyll: The Role of the First «Bräutigam» in Goethe's Hermann und Dorothea", The German Quarterly 54/4 (1982), pp. 532-544.

19 J. W. von Goethe, Hermann und Dorothea, Stuttgart, Reclam, 1996, p. 66. A partir de ahora citado como HD. 
cuando sus palabras burlonas hayan humillado a la joven Dorothea, anunciará que prefiere subir a su cuarto a dormir para evitar los "lamentos de las mujeres y el griterío apasionado" 20 . Frente al rechazo de toda curiosidad hacia los sufrimientos ajenos por el padre de Hermann, el boticario relata la trágica inversión que representa la masa de emigrados con una consciente écfrasis de los bienes que constituyen a los sujetos:

Era triste ver los múltiples bienes que había contenido una casa, de manera ordenada, y que un buen dueño antiguamente había colocado cada uno en su lugar, siempre dispuesto al uso, pues todo es necesario y útil. Ahora vemos todo eso amontonado confusamente en carros y carretas, con la precipitación de la huida. Sobre el armario está la criba y la manta de algodón, la cama en la artesa y los paños sobre el espejo. $¡$ ¡Ay! El peligro arrebata al ser humano toda reflexión, como hace veinte años comprobamos nosotros. Toma lo insignificante y deja lo estimable ${ }^{21}$.

A esta escena en que las cosas hablan de la existencia humana sucede la descripción de un terrible accidente sufrido por la vertiente más vulnerable de la muchedumbre, a saber, mujeres y niños agobiados, ancianos y enfermos balanceados en lo alto de carros sobrecargados, a los que se suman el balido de algunas ovejas y el ladrido de los perros. Ese sonido humano animalizado se une al descarrilamiento de una carreta que deja con vida, pero sin socorro a un grupo numeroso de desgraciados, desasistidos por compañeros que continúan su huida sin fin. En este contexto de desesperación y egoísmo Hermann, enviado por sus padres a entregar dones con que socorrer a los refugiados que cruzan sus tierras, se encuentra por primera vez con Dorothea, una muchacha que asiste heroicamente a una parturienta, de cuya familia se ha hecho cargo en la huida. Esa visión le lleva a enamorarse de ella y señala el comienzo de una transformación paulatina del muchacho, que por la relación casi vampírica que inicia con Dorothea le va restando su epicidad original, asumiendo él mismo ese rol heroico. Nadie sabe quién es la muchacha, a qué familia pertenece, de qué localidad del otro lado del Rin procede, pero la madre del joven convence al pastor y al boticario para que se informen acerca de su carácter. En sus pesquisas topan con un venerable juez que ejerce de líder de los refugiados, comparado con una suerte de Moisés o Josuée ${ }^{2}$, que se duele de su suerte y muestra su admiración ante la valentía con que las mujeres se han conducido en la larga marcha hacia ninguna parte:

He visto al sexo débil, como se le suele llamar, realizar actos asombrosos de energía, de valor y de presencia de espíritu; permítame que entre todos le señale a una heroica muchacha; había quedado con sus compañeras en una quinta aislada mientras los hombres iban a hacer frente al enemigo. De pronto, una partida de fugitivos se precipitó en el patio, se entregó al pillaje y penetró hasta la habitación donde estaba refugiadas esas desgraciadas mujeres; la mayor parte de estas eran casi niñas. Un deseo desenfrenado se apoderó de aquellos miserables; se lanzaron sobre el grupo tembloroso, ante el cual se erguía la valiente muchacha de que le

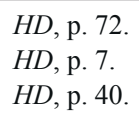


hablo. Sin titubear arrebató el sable a uno de ellos y le asestó un violento golpe en la cabeza que le tendió muerto a sus pies. Después, con la misma intrepidez, golpeó a otros cuatro, que escaparon de la muerte por pies, libra así a sus compañeras y fue a atrancar la puerta de la casa aguardando socorros y sin abandonar las $\operatorname{armas}^{23}$.

Todo parece anunciar que la muchacha es la adecuada para contraer matrimonio con Hermann, con mayor acierto que la hija de comerciante que su padre espera ver convertida en su esposa. Su carácter recio es asimismo consonante con la historia que recuerda el juez: la muchacha estuvo prometida a un revolucionario alemán, probable miembro del Club jacobino para la Libertad y la Igualdad, que acude a París para satisfacer sus ansías de transformación del mundo mediante la tormenta revolucionaria, encontrando allí la muerte. Como señalábamos antes, se trata de un destino muy similar al que Georg Forster encontrara en enero de 1794 en una oscura buhardilla parisina, como representante de la efímera República de Mainz. Podría intentarse encontrar en los rasgos épicos de Dorothea el coraje vital mostrado por Theresa Huber, esposa de Forster, a la que la admiración por la causa revolucionaria no condujo a perder la cabeza y poner en riesgo su seguridad y la de sus hijos, sino a contraer un segundo matrimonio con Ludwig Ferdinand Huber, que contará con la solidez y paz que faltó al primero. A pesar de que el fantasma del trasunto poético de lo real es insidioso, volvamos a detenernos por un momento en la ficción y concretamente en la inversión que esta propone de los roles iniciales de la mujer y el varón. Cuando Hermann vuelva a encontrar a la joven, con la intermediación de un elemento generador de tantas ilusiones como el agua, no será capaz de pronunciar ninguna declaración de amor, pues "su mirada [de Dorothea] no emite amor, sino claro entendimiento y ordenaba hablar razonablemente"24. Urgido por la situación, hará a la muchacha una propuesta mediocre, en principio más acorde con la disparidad de condiciones en que ambos se encuentran y con las expectativas del género femenino, consistente en darle acogida como sirvienta en la casa de sus padres. "Una muchacha siempre tiene que servir [Überall dienet das Mädchen] ${ }^{\prime 25}$ pronuncia entonces Dorothea, asumiendo que ingresar al servicio de la madre de Hermann es el mejor destino que le puede deparar su situación presente, en buena parte por resultar connatural a su género. Por otra parte, la familia de la que ha estado cuidando en la huida ya se encuentra en mejor disposición de cuidar de sí misma. Dorothea puede pues ocuparse de su futuro con la conciencia tranquila. A pesar de la invocación a las Musas de Goethe para no marrar en la exposición del lazo que unirá a la pareja, o quizás precisamente como parte de la voluntad de estilo del poeta, cuando el padre de Hermann vea aparecer a Dorothea le hará sonrojarse con comentarios soeces para una joven, preciándose del buen gusto con las mujeres que su hijo ha heredado de su progenitor. Hermann, incapaz de tomar las riendas de la situación, irá de angustia en angustia para salir del enredo, solicitando para ello ayuda al pastor. Dorothea insiste en volver al campamento de los refugiados y asumir que pertenece a ellos, pero la sensibilidad y finura de la madre de Hermann le hará deponer su actitud y aceptar el lazo con Hermann, un vínculo que le obliga a recordar la historia de su primer pro-

\footnotetext{
$H D$, pp. 45-46.

$H D$, p. 54.

$H D$, p. 58.
} 
metido. Si aquel revolucionario alemán traicionó a su patria -en efecto los decretos del Emperador Francisco II perseguían a revolucionarios como Forster-, el desenlace del poema se condensa en la fundación de un orden familiar y civil por parte de Hermann y Dorothea, que evoca la unión que los padres de Hermann sellaran en medio de un desolador incendio. El discurso que el primer enamorado de Dorothea dedica a dar razón del desorden en que se encuentra la Europa en el periodo postrevolucionario emite en los versos de Goethe un tono evocador de algunas cartas finales de Forster, que ni siquiera en la fase del Terror fue capaz de renunciar a un proceso revolucionario que definía como un huracán llamado a destruir todo lo que encontrara a su paso. Pero la actitud del revolucionario ante la violencia circundante no puede ser aprobada por Goethe, toda vez que los rasgos predominantes en esta actitud son los de una pasividad inconsistente con la libertad humana:

Todo se estremece sobre esta tierra, todo parece que va a disolverse; las leyes fundamentales de los Estados son derrocadas; el antiguo patrimonio escapa a su propietario; el amigo abandona a su amigo y el amante a su amante. [...] Con razón se ha dicho: el hombre no es más que un extraño aquí abajo; y más que nunca esto es verdad. Nuestro cielo ya no es nuestro. [...] Todo se agita en desorden, como si el mundo actual fuera a caer en la noche del caos para volver a surgir bajo una nueva forma ${ }^{26}$.

Frente a la aceptación del caos como la ley que rige la historia, los versos finales del poema se proponen invertir esta presuposición, devolviendo a la acción humana al lugar esperable como preparación del camino para la paz. En el marco esbozado por Hermann, la disposición hacia la defensa del débil manifestada por Dorothea en la obra caerá como por arte de magia del lado del esposo, concentrándose la mujer en el cuidado de los ancianos padres y la casa, como corresponde a la saludable identidad nacional:

¡Qué nuestra unión, Dorothea, sea tanto más sólida en medio de la conmoción general! Queremos permanecer tranquilos y fuertes ante la tempestad y de mantener firme la posesión de los bellos bienes. Pues el hombre que tiene un temple de ánimo falto de decisión en una época turbulenta aumenta aún el mal y lo extiende más y más. Sin embargo, quien se mantiene firme en su sentido, ese se construye el mundo. No conviene al alemán propagar ese terrible movimiento ni flotar de aquí para allá. ¡Esto es nuestro, digamos y afirmemos así! Sea homenaje eterno a los pueblos resueltos que se sublevan para rechazar al enemigo, para proteger su religión, sus leyes, sus mujeres y sus hijos. Me perteneces; y lo mío es más mío que nunca. No quiero conservar la preocupación ni disfrutar con inquietud, sino con arrojo y fuerza [...] Y si todos pensáramos lo mismo, el poder se opondría al poder, y nos regocijaríamos todos de la $\mathrm{paz}^{27}$.

Como mujer refugiada y lastrada por un pasado revolucionario, Dorothea se ve así expropiada de las características que la han vuelto atractiva en el idilio burgués, mostrando en su intento de abandonar las dificultades en que se encuentra una angus-

\footnotetext{
$H D$, p. 74.

$27 \quad H D$, pp. 75-76.
} 
tia por apropiarse de identidades ajenas -la de la mujer alemana comme il faut-que Arendt califica como rasgo común de todos los refugiados en $1943^{28}$. Toda apropiación de identidad es buena si rebaja el sufrimiento por la indeterminación. Dorothea cede sus energías heroicas a Hermann, a partir del pacto que estrechan al reflejarse ambos sobre la superficie de las aguas, mereciendo por ello el milagro de la asimilación y el olvido de la Schande, a saber, la marca de lo abyecto que poco más de un siglo más tarde portarán "los buenos europeos", como el K. de El castillo de Kafka, confiados en que basta con querer ser ciudadano para serlo. Frente a ese amargo sueño, Goethe impone con ironía la certeza del mesonero de Hermann y Dorothea acerca de que el peor de los males es la inquietud, y esta siempre suele ir de la mano de la precariedad y la pobreza. Únicamente se libran de ella los buenos burgueses, orgullosos de haber hallado su tabla de salvación, aun al precio de sentenciar a un destino abyecto a quienes se extiendan sobre la espalda del mundo.

\section{Conclusiones}

A la luz de las consideraciones precedentes esperamos haber arrojado algo de luz sobre la funcionalidad que la trama de Hermann y Dorothea de Goethe posee para plantear la historicidad de la percepción del refugiado en la literatura europea. Los escritos de Goethe en los que describe el campo de batalla y en que lo adopta como espacio de ficción ponen de manifiesto una tendencia casi obsesiva para legitimar el mantenimiento del orden institucional y moral burgués por encima de cualesquiera otras consideraciones propiciadas por la exclusión social que pone en marcha la dinámica bélica. El personaje de Dorothea ofrece un perfil óptimo para proceder a una negociación entre el espacio representado por la casa y el orden civil y el caos causado por la violencia, proceso del que se deriva finalmente la imposición de los valores y principios propios de un varón, heredero de un patrimonio familiar que invoca al culto debido a los Penates germanos frente a las aciagas utopías de la filantropía cosmopolita. La intención principal de este texto ha sido la de proponer una lectura del idilio de Goethe en la que la ambivalencia de rasgos de la pareja protagonista desemboca en el desenlace de la decisión por la solución justa y necesaria.

28 Cf. H. Arendt, "Nosotros los refugiados" (publicado en 1943 en The Menorah Journal), en ibidem, Una revisión de la historia judía y otros ensayos, Paidós, 2005, pp. 13-14: “A uno le puede sorprender que la evidente inutilidad de todos nuestros falsos disfraces no haya sido todavía capaz de desalentarnos. [...] Pero antes de lanzarnos la primera piedra, recuerda que ser judío no da ningún reconocimiento jurídico en este mundo. Si empezáramos contando la verdad de que no somos sino judíos, ello supondría exponernos al destino de los seres humanos que, sin la protección de ninguna ley o convención política concreta, no son nada más que seres humanos. Apenas puedo imaginarme una actitud más peligrosa, puesto que vivimos de hecho en un mundo en el que los seres humanos como tales han dejado de existir por un buen rato; puesto que la sociedad ha descubierto en la discriminación la gran arma social con la que uno puede matar hombres sin derramamiento de sangre; puesto que los pasaportes o los certificados de nacimiento, y a veces incluso los recibos del impuesto sobre la renta, ya no son papeles oficiales, sino cuestiones de distinción social". Sobre las tesis contenidas en este ensayo de Arendt remito al artículo de S. Fantauzzi "Para no ser solamente víctimas", Oxímora 11 (2017), pp. 78-92 y a los trabajos de N. Sánchez Madrid, "El pensamiento judío en Arendt: resistir ante la destrucción de lo humano", en E. Zazo/R. Navarrete (eds.). El pensamiento judío ante la catástrofe, Barcelona, Herder, 2019a (en prensa) y "Arendt y la vergüenza de la falta de lugar: procesos de perversión de la condición humana", en L. Acosta/P. López Álvarez (eds.), La técnica moderna y las "superaciones del hombre”. Mutaciones de la experiencia, 2019 b (en prensa). 
Las consideraciones del autor acerca del absurdo que prolifera en tiempos de guerra suministra el telón de fondo histórico en que surge una obra de ficción que transmite al lector que el desorden no ha de ser nunca la última palabra mientras la existencia humana siga estando presente sobre la Tierra. El ruido de las armas no amenaza la vigencia de las leyes, a juicio de Goethe, toda vez que la unidad familiar seguirá reclamando para sí la autoridad de desplegar un tejido civil a partir del cual las naciones podrán volver a recomponer sus pecios. En esa determinación [Bestimmung] de la especie humana ${ }^{29}$ una muchacha como Dorothea debe sacrificar sus rasgos heroicos para reconocer en su plena valía la virtud del varón, único agente llamado a regenerar los vínculos sociales y políticos. El pasado de la muchacha, así como una pareja anterior -un revolucionario radical, solo sirven para subrayar con mayor énfasis el acierto de la elección que conduce a Dorothea a compartir su existencia con una familia de hosteleros, en la que el culto a la calma se impone sobre una inquietud, que a veces aparece con la duda, el titubeo o la indeterminación, pero siempre acaba por identificarse con la llegada de la peste. No resulta difícil reconocer bajo la figura del padre de Hermann, el muchacho cargado de responsabilidad y promesa de futuro, la misma displicencia que Goethe dedicara a fenómenos como el dolor, el sufrimiento y el desajuste mundano y vital, a los que solo convertirá en eje de su pensamiento para dibujar a un profeta del dandismo afectivo como Werther, esto es, para calibrarlos en tanto que mercancías valiosas en sociedad.

29 Una monografía determinante para el análisis de este concepto epocal central para la Ilustración alemana desde sus inicios, cuya actualidad alcanza los primeros compases del Idealismo alemán, es la de L. Anna Macor, Die Bestimmung des Menschen. (1748-1800): Eine Begriffsgeschichte. Forschungen und Materialien zur deutschen Aufklärung, Stuttgart-Bad Cannstatt: Frommann-Holzboog. 